He did not complain of headache, but two days after admission lie began to have some disturbance of accommodation, not being able to say whether an object was near or at a distance. At this time he also commenced to have typical myoclonic movements of the right iliac region, most marked in the rectus muscle. He lad very marked hyperaesthesia of the $\mathrm{skin}$ of the :ight side of the abdomen; deep pressure was, howerer, not very painful-apparently a fact of some importance in diagnosis. His knee-jerks were markediy exaggerated, and in a short time the myoclonic movemarkediy exaggerated, and in a short time the myoclonic moveright. The pain was of such severity that large doses of morphing were given. In the first twenty-four hours after admission lic had no fewer than five injections of $1 / 4$ grain without any apparent effect.

The absence of reaciion to morphine in the cases which I have seen is very striking, and would seem to have some diagnostic importance. There happened to be a case of tetanus in the ward at the time, and I suggested that as the cases seemed very similar intramuscular injections of magnesium sulphate might be tried. This procedure seemed to make the patient so much worse that only two injections were given. The maximum temperature in this case during seven days was only $99^{\circ}$, and the pulse varied between 70 and 80, although it was obvious that the man was acutely ill and suffering agonizing pain.

\section{Case III.}

Miner, aged 40. Admitted August 27th, 1924. The diagnosis on admission was "acutc abdomen"-(?) strangulated hernia. The patient gave a history very similar to Case II. Four days prior to admission he had some slight pain over the left inguinal region, which rapidly became worse and shot down into the left testicle. The patient described the pair as being "jerky" in character. He had vomited repeatedly, had fairly severe headache, and on admission had retention of urine. No hernia could be made out.

On admission there were strong myoclonic movements of both sides of the abdomen and marked skin hyperaesthesia. The kneejerks wiere exaggerated and myoclonic movements of the legs were commencing. He complained of no eye symptoms, but lateral nystagmus was present, the significance of which was doubtful nystagmus was present, the significance of which was doubtful owing to his occupation. He had also severe pain in the left not above normal, and morphine had no effect on the pain; hyoscine, not above normal, and morphine had no
however, seemed to quieten the spasms.

$$
\text { CASE IV. }
$$

Clerkess, aged 17. Admitted August 15th, 1924. The diagnosis on admission was acute appendicitis. The patient stated that on August 12th she was seized with acute pain on the right side of the abdomen. She had vomited repeatedly, was conside of the abdomen. She had vomited repeatedly, was con-
stipated, and had severe headache. Her temperature on admission stipated, and had severe headache. Her temperature on admission
was $102.8^{\circ}$, pulse 100 , and respirations 22 . During the period of was $102.8^{\circ}$, pulse 100 , and respirations 22 . During the perio

Whervation the temperature remained moderately elevated.
When saw her shortly after admission she was very restless and resembled a case of chorea. She was inclined to be hysterical, and her answers were unreliable. The skin of the right side of the abdomen was very hyperaesthetic, and deep pressure was not allowed. She had no local myoclonic movements, although generalized choreic movements were present. Her mental attitude was so peculiar that I decided not to operate and observed the patient for some days. In the interval I saw her own medical attendant, who told me that he had been in doubt regarding some of her symptoms, but had eventually diagnosed appendicitis. On August 17th, as she was still running a high temperature and fairly rapid pulse, I asked a physician to see her. He gave the opinion that he considered that we were justific d in exploring the abdomen. I therefore opened the abdomen over the appendix region on August 18th. I found a perfectly normal appendix, but there were numerous enlarged mesenteric glands. I removed a
gland for examination, and this was returned as being "chronic

inflamm for exantory."

Her condition did not improve after the operation and it was reported to me that she was becoming increasingly noisy at night, throwing off the bedclothes, taking off her nightdress, and behaving generally like a naughty child. During the day she lay perfectly quiet and resented any examination in such a manner that one got the impression of imbecility. The temperature remained high (103 ${ }^{\circ}$ in the evenings). The knee-jerks were absent at this period and she appeared to have a positive Kernig's sign. There was no neck rigidity and no very definite evidence of tuberculous meningitis, which had been suspected when the enlarged glands were found.

She was again examined by the physician, who now gave an opinion that the case might be one of encephalitis, although he would not say this definitely, the symptoms being so obscure.

If this diagnosis is correct wo have a case beginning with abdominal pain and not developing the typical myoclonic movements, tending rather to pass straiglit into the more lethargic type of the disease.

Dr. Middleton has informed me (about September 10th) that the abdominal wound suppurated to some extent and that the condition of the patient has improved as regards pulse and temperature. She still remains in a curious mental condition, but has not developed anything else to make him give a definite diagnos's of encephalitis.
I merely quote the case as illustrative of one in which encephalitis had to be considered, although the definite enlargement of the abdominal glands might indicate another infection.

\section{Conclusions.}

From the very limited experience of a surgeon in such cases I would say that the following points are of importance in diagnosis.

1. Myoclonic movements, if present to any extent, are characteristic of the type of the disease likely to be mistaken for the acute abdomen, and once those have been seen in a typical case the observer is not likely to mistake them for anything else, although in the cases reported those had evidently been mistaken for the movements of a patient in pain. The movements show themselves as fairly rhythmio contractions of groups of muscles, and not at all as the muscular rigidity characteristic of acute abdominal lesions. In the cases under discussion the recti and obliques were the muscles principally involved. Needless to say, a patient with an acute intra-abdominal lesion does not willingly move the muscles of the abdominal wall to any great extent, and it is very remarkable to observe the intenso pain produced by the involuntary myoclonic movements in a patient suffering from encephalitis. Unfortunately the movements appear to follow the pain, the interval varying in length, and herein lies the difficulty in diagnosis.

2. Eye symptoms (double vision, disturbances of accommodation, nystagmus, irregular pupillary reflex) if present are of great value. Headache as a first svmptom is also of some value, and pain in a site removed from the main site complained of would also appear to be significant, as in Case III, where there was pain in a hand and a foot in addition to the abdominal pain.

3. S'liin hyperclesthesia in the cases I have observed has been very marked and has been much more widespread thim is the case in the ordinary acute abdomen.

4. Pulse and temperature in three out of the four casers were hardly affected.

5. Lethargy, in the early stages of the myoclonic type of the disease at least, seems often to be notable by its absence.

The disease in the myoclonic form resembles tetanus in many respects, but the muscle spasms are in the nature of a clonus and there is not the tonic spasm found in tetanus. External stimuli, such as an examination of this patient or the banging of a door, tend to produce an exacerbation of the symptoms, and the spasms start in one group of muscles and afterwards spread over the body, retaining, however, their clonic character. Chorea and hissteria are also likely to pass through the mind of the medical officer examining such a case. I have already discussed the question of the acute abdomen.

My only object in trespassing on the phrsician's domain is to draw attention to the fact that these cases are being mistaken for surgical conditions, and I must apologize to my readers for the somewhat inadequate notes. I also write in the hope that other's will give us guidance in the question of early diagnosis.

I am indebted to Mr. Paterson for his permission to describe the cases seen in his wards and to Drs. Harrington and Middleton for their help in consultation.

\section{SPONTANEOUS RUPTURE OF THORACIC AORTA.} BY

C. DUNDAS MAITLAND, M.B., F.R.C.S.Evg., HONORARY MEDICAL OFFICER TO OUT-PATIENT DEPARTMENT, ROYAL SLRIEY COUNTY HOSPITAL.

Sposmeseus rupture of the thoracic aorta as a sequel to an operation for gangrene of the leg is a sufficiently raro event to justify the following report.

A small, thin, rather cachectic-looking man, aged 49, had spent most of his life in mining work in Burma, where he had suffered from beri-beri and malaria. His work, he stated, was largely in wet boggy country, so that for years he was almost continualiy getting his feet bathed in water and mud. I was first called to see him about six months before his death for an attack of abdominal pain which was diagnosed by Dr. Paget-Jones of Horsley, Surrey, as due to appendicitis; I agreed wih this diagnosis and operated the following day, removing a subacutely
inflamed appendix. During the rouline preoperative cxamination 
Dr. Paget-Jones noticed that the aortic second sound was not clear, and that there was a faint mitral murmur; the urine was free from albumin and sugar. The patient stood the operation perfectly and made an uninterrupted recovery, there being no disturbance of the heart or

Two months later his doctor again asked me to see him on account of acute pain and tenderness in the left scrotal sac and along the course of the left vas deferens. I found a condition of acute deferentitis and funiculitis. Prostatic massage produced an exudate fairly typical of chronic gleet. At this time a history of gonorrhoea many years ago was obtained, but the patient persistently denied any history of syphilis, although pressed strongly on that point. He was treated by rest, urinary antiseptics, fomentations, and careful dieting, with the result that all pain and swelling disappeared in about a week, and he returned to his daily work,
travelling up to his London office and appearing to be in his usual health.

Shortly after this his heart began to give trouble, and I again saw him in a condition of acute auricular fibrillation. At this time Dr. Paget-Jones had already got him under treatment; he was quite unable to walk, was slightly cyanosed, and severely dyspnoeic. mitral mun to the auricular fibrillation there was a rushing double mitral murmur with marked left-sided dilatation, and the aortic though we were unable to detect any actual murmur. $\Lambda$ very rigid course of treatment with graduated doses of digitalis and potassium codide, combined with absolute rest and careful dieting for about two weeks, was followed by a very gradual return to normal two weeks, was followed by a very gradual return to normal
activities. At the end of another month, Dr. Paget-Jones informed me, the patient had resumed his business life, and the heart seemed to have so completely recovered that nothing abnormal could be detected by stethoscopic examination.

About six weeks before his death I was again called into consultation. When I saw him he was suffering great pain in the legs, and both were showing blue-black patches of commencing gangrene below the knees, the right being considerably worse than the left. The history was that three days previously he had noticed some numbness in the feet " as if he were walking on wool " and of ten noticed the same feeling when they vere constantly getting often noth mud in Burma. The following day, however, getting dark blue indurated plaque, about 3 inches in diameter, formed in the right calf apparently just beneath the skin. He then sent for Dr. Paget-Jones, wh' at once noticed a slight commencing cyanosis Dr. Paget-Jones, whis at once noticed a slight commencing cyanosis in the dorsalis pedis, calcaneal, and popliteal arteries of both lecs. He suspected the onset of gangrene, and diagnosed the indurated He suspected the onset of gangrene, and diagnosed the indurated
lump as a subcutaneous haemorriage. When seen by me the next lump as a subcutaneous haemorriage. When seen by me the next day (fourth day after onset) it appeared quite certain that was not too far gone to recover. The heart was again fibrillating, though not so badly as in the previous attack, the mitral murmur had recurred, and the aortic sound was blurred and prolonged.

'The patient was immediately removed to the Royal Surrey County Hospital, where Dr. Mitchell took charge of his medical treatment, which consisted essentially of 30 -grain doses of potassium iodide thrice a day and daily intravenous injections of strophanthin. This was continued for twelve days, during. which time the feet were kept continually elevated, powdered with sterilized boric powder, wrapped in thick layers of sterile wool, and the whole cradle wrapped in thick layers of sterile wool, and the whole cradle covered with a large radiant heat bath which was kept going continuously. Under this treatment the left leg recovered completely as regards colour, warmth, and sensation, but circulation
could not be felt in any arteries below the knee. The line of could not be felt in any arteries below the knee. The line of demarcation on the right leg sank from just below the knee to remained quite aseptic and dry. Meanwhile the heart had improved so much that I felt justified in attempling amputation in the lower third of the thigh. The urine was carefully examined in hospital and found to cortain a very slight trace of albumin, but no sugar or acetone. The blood Wassermann reaction was found to be positive. The blood count was normal except for slight leucocytosis cent. The blood pressure was : systolic $161 \mathrm{~mm}$. and diastolic $95 \mathrm{~mm}$. Hg.

On the twelf th day of hospital treatment-that is, the sixteenth from the onset of trouble in the legs-I performed the amputation after first blocking the sciatic nerve in the buttock by a local deep injection of $20 \mathrm{c.cm}$. of 1 per cent. novocain solution directly into injection of $20 \mathrm{c.cm}$. of 1 per cent. novocain solution directly into the nerve trunk. This was combined with a very small amount of pleted in thirty-five minutes. The patient stood the operation pleted in thirty-five minutes. The patient stood the operation the first five post-operative days everything appeared to be progressing perfectly. The flaps retained normal sensation, warmth, and colour, and appeared to be uniting firmly; there were no "starting pains" or pain of any description except a little soreness around the site of the injection in the buttock.

On slitting up the popliteal artery in the leg after its removal, it was found to have a lumen less than half the normal, and to have grossly thickened fibrous walls, but there was no naked-eye evidence of ulceration or calcareous changes in the intima of the vessel, and no thrombus was found. On the morning of the sixth day aiter operation the patient felt so well that, wishing to be uncluly independent of nursing assistance, he sat up in bed, attempting to shave himself. He was then noticed by one of the nurses to fall suddenly forward without uttering a sound. him dead.
Post-mortcm Examination.

A necropsy was performed the same day and the following remarkable condition was found. The heart was dilated and the musculature felt hard and fibrous. The mitral valve appearcd healthy, as did the whole of the endocardium with the exception of the aortic valves, which were thickened and more inelastic than usual, but not grossly diseased. There was a slight excess of clear fluid in the pericardium. The right lung appeared healthy, the huge collection of non-coagulated and clotted pure blood which completely filled the whole of the left pleural cavity. The heart, completely filled the whole of the left pleural cavity. The heart, aorta, venae cavae, trachea, and lungs and oesophagus were
removed cn masse to avoid any possibility of accidental injury to removed $c n$ masse to avoid any possibility of accidental injury to any part of the main vascular system, from which it was
such a rapid and profuse haemorrhage must have issued.

It was then observed that no aneurysm was present, and that the aorta was rather smaller than normal and of uniform calibre throughout its length as far down as the diaphragm, at which level it had been divided for removal. The aorta was divided from end to end with very blunt-nosed scissors and then carefully examined for a rupture. This was discovered in the form of a 1 inch split situated on the convex surface of the aortic curve half an inch distal to the site of junction of the left common carotid artery. The thickened, rigid, brittle aortic wall was so grossly diseased that the artery cracked audibly when bent or compressed between the fingers. This was due to the extensive calcareous changes which had taken place throughout the whole length of the vessel; calcareous plates 1 inch square could be stripped out the vessel; calcareous plates 1 inch square could be stripped out without any difficulty. The muscular and external adventitious coats could be readily stripped from each other by simple traction with the fingers, and the calcareous plates appeared to be embedded
in, and to have largely replaced, the muscular coat. No gross in, and to have largely replaced, the muscular coat. No gross change was to be seen in the intima, though there were numerou
small areas of shallow atheromatous ulceration and proliferation.

The whole history of this case points to the gangrene having been due to syphilitic endarteritis obliterans rather than to any embolic blocking. The most remarkable feature was that the patient should have been able to carry on a normal active business life and to survive successfully two general anaesthetics up to within such a short time of his decease with such an advanced degree of degeneration present in his main arterial channel.

\section{Atlentoranda :}

\section{MEDICAL, SURGICAL, OBSTETRICAL.}

\section{ANEURYSM OF A BRANCH OF THE RENAL ARTERY.}

I was very interested in Mr. R. P. Rowlands's article in your issue of November 22nd, 1924 (p. 939), on aneurysm of a branch of the renal artery. I think the following case of painless haematuria may prove of interest, and was possibly due to the same cause.

A man, aged 59, previously quite healthy, consulted me on August 14th, 1924, for profuse painless haematuria of sudden onset. The urine contained a very large quantity of bright red blood, and in the first specimen seen was a ureteric cast. Microscopically there was blood only, and no neoplastic cells were detected. Later, very slight ureteric colic occurred, with tenderness of the kidney on the right side. There was no history of trauma or of previous pain. A radiograph negatived stone, but gave definite evidence of slight enlargement of the right kidney. Severe painless bleeding constrating by cystoscopy profuse haemorrhage from the right ureter and a stream of clear urine from the left. Some of the urine from the left kidney was collected and was found to contain 2.2 per cent. of urea. Profuse haemorrhage persisted for the next forty-eight hours, and on August 21st I explored the right kidney through the loin, having diagnosed provisionally renal neoplasm. The organ was adherent, enlarged, and deeply congested. No stone or difference in consistency could be detected. As the stone or difference in consistency could be detected. As the haemorrhage was just as profuse and continuous as ever, and the formed without first opening the kidney. The patient made an uninterrupted recovery.

On splitting the kidney, after removal, the knife bisected in the pelvis a globular mass the size of an olive, which appeared to consist of laminated blood clot, exactly comparable to that found on the walls of some aneurysms.

Pathological Report.

The whole organ was sent to the Clinical Research Department, St. Bartholomew's Hospital. The reports were as follows :

"A Asust 30th.-Macroscopically the kidney shows several subcapsular' haemorrhages and subepithelial haemorrhages in the pelvis. There is a larger haemorrhagic area in the pelvic fat, in close relation with the pelvis, measuring roughly 2 by 1 by $1 \mathrm{~cm}$. A section has been prepared from this area. It shows irregular appears normal and there is no evidence of new growth. Arcund 